\title{
On the (Mis)classification of Paid Labor: When Should Gig Workers have Employee Status?
}

\author{
Daniel Halliday \\ University of Melbourne, Australia
}

\begin{abstract}
The emergence of so-called 'gig work', particularly that sold through digital platforms accessed through smartphone apps, has led to disputes about the proper classification of workers: Should platform workers be classified as independent contractors (as platforms typically insist), or as employees of the platforms through which they sell labor (as workers often claim)? Such disputes have urgency due to the way in which employee status is necessary to access certain benefits such as a minimum wage, sick pay, and so on. In addition, classification disputes have philosophical significance because their resolution requires some foundational account of why the law should make a distinction between employed and freelance workers in the first place. This paper aims to fill this foundational gap. Central to it is the idea that employment involves a worker ceding certain freedoms in return for a degree of security, at least with respect to income. Insofar as the misclassification objection has force against digital platforms, it is when a platform is attempting to have it both ways: Workers are giving up freedom but not being granted a proportionate increase in security. As I shall explain, this approach offers some flexibility as to how actual disputes might be resolved - justice may be indifferent between whether platforms offer greater security or permit workers greater freedom, provided they do at least one of these things.
\end{abstract}

\section{Keywords}

gig economy; digital platforms; labor markets; employment; freedom; justice; worker classification

\section{Introduction}

In recent years we have become familiar with a range of digital platforms, accessed through our smartphones, through which we buy services like car rides and food deliveries. Such platforms are mainstays of the 'gig economy' -a section of the labor market in which workers sell their labor in an allegedly new, flexible way, free from the constraints of traditional employment. ${ }^{1}$ Controversy about how these platforms are allowed to operate motivates an effort to gain clarity on a distinction that lacks a sustained theoretical treatment in political philosophy: What determines whether a person works for themselves rather than for an employer? This paper develops an answer to this question, with a view to applying it to the controversy about worker classification.

A common complaint about digital platforms is that they misclassify the labor sold through them, by declaring workers freelance contractors rather than employees. We can call this the 'misclassification objection'. Employee status triggers a number of legal

\footnotetext{
${ }^{1}$ As I will explain below, platforms may be new but gig work in a theoretical sense is not. This undermines certain narratives about the 'revolutionary' features of digital platforms. A useful comment on these narratives and their potential impact on academic debates is Pasquale (2016).
} 
entitlements not accrued by freelancers. So, worker classification makes a difference to the costs and benefits enjoyed by workers and those to whom (or 'through' whom) they sell their labor. Accordingly, misclassification by platforms, to the extent that it occurs, looks like a labor market injustice: It denies workers an entitlement they should hold, given the kind of work they provide. Although the distinction between employees and freelance workers has long existed in law, its foundations, and hence its boundaries, remain obscure. Such obscurity may be tolerable so long as there are no disputes between workers and owners of capital as to how the workers should be classified. But actual disputes have by now become common. ${ }^{2}$ Courts and governmental agencies in various jurisdictions have been forced to take a view on how to correctly classify platform workers, particularly in the rideshare sector. This has proven difficult to do. ${ }^{3}$ At any rate, different jurisdictions seem to have gone in different directions when choosing what view to take. The Appeals Court of England and Wales, for example, recently concluded that Uber drivers are employees, on grounds that drivers cannot negotiate with customers on price - this being set by the platform's algorithm. ${ }^{4}$ In Australia, the Fair Work Ombudsman drew the opposite conclusion, determining that Uber drivers are selfemployed due to their ability to choose which (and how many) hours to work. ${ }^{5}$ In the United States, the California Assembly has since passed legislation approximating an intermediate position between the English and Australian ones. ${ }^{6}$

Jurisdictions vary as to their background employment law, including what precedents have been set and the weight given to them. Actual disputes around worker classification have in some countries not run their full legal course, and in any case the body of law around gig work is still in the early stages of what might be a long evolution. ${ }^{7}$ But the business model of the relevant digital platforms remains much the same from place to place. After all, Australian Uber drivers are just like English drivers in being unable to negotiate on price, and drivers in both countries (and elsewhere) are also alike in being able to choose which hours to work. A plausible view is that each decision highlighted some relevant consideration(s), but lacked the benefit of a more comprehensive framework for identifying the totality of considerations and weighing them against one another. One gets the impression that, in the end, current practice is arbitrarily privileging single considerations as decisive, hence the discrepancy of judgments across

\footnotetext{
${ }^{2}$ For some background see Acevedo (2018), Pinsof (2016).

${ }^{3}$ See for example Prassl \& Risak (2015).

${ }^{4}$ For the full judgment see https://www.judiciary.uk/wp-content/uploads/2018/12/uber-bv-ors-vaslam-ors-judgment-19.12.18.pdf (accessed 2/2/2020). As the final version of this paper was prepared for publication, the UK Supreme Court issued a judgment upholding that of the Appeals Court: https://www.supremecourt.uk/press-summary/uksc-2019-0029.html (accessed (4/4/2020)

${ }^{5}$ For an official press release see https://www.fairwork.gov.au/about-us/news-and-mediareleases/2019-media-releases/june-2019/20190607-uber-media-release (accessed 2/2/2020)

${ }^{6}$ For the complete bill, see https://leginfo.legislature.ca.gov/faces/billTextClient.xhtml?bill_id=201920200AB5 (accessed $2 / 2 / 2020$ )

${ }^{7}$ On this, with special attention to US law, see Acevedo (2020).
} 
jurisdictions. Where the academic study of gig work is deferential to actual legal reasoning, these discrepancies seem to be getting reiterated. ${ }^{8}$

The goal of this paper is to examine the more theoretical question of why an employee/freelancer distinction might be desirable in the first place, and how attention to this can help us reach an understanding of what its content should be. I will argue in what follows that the employee/freelancer distinction embodies a set of tradeoffs that workers must resolve when deciding what kind of work to seek in labor markets. This tradeoff consists in the acceptance of some set of risks in return for various freedoms specific to labor market participation: Freelancers accept risks in return for freedoms, whereas employees cede at least some freedoms (to their employer) in return for certain guarantees (either from their employer or more directly from the state). I make this proposal not as a descriptive claim about how any jurisdiction's existing employment ought to be interpreted based on what it already says, but as a normative claim about what employment law and policy, on these matters, should say.

I shall argue, further, that the misclassification problem with digital platforms has force to the extent that digital platforms fail to respect the kind of tradeoff just outlined. This happens when platforms treat workers like employees by denying relevant freedoms but as freelancers when imposing relevant risks. This will vindicate some real-world expressions of the misclassification objection where platforms are 'having it both ways'. As a general position, however, it needs to be qualified: Digital platforms differ in their business models and their treatment of workers accordingly, and there is no reason why their existence should be seen as an injustice to workers merely by default. Instead, the philosophical contribution lies in providing the sort of theoretical substance that can help diagnose when platform work is morally problematic in its treatment of workers and when it is not, and in providing philosophical support for how future regulation of platforms might be designed. Accordingly, plausible proposals for greater regulation of platforms should aim at offering platforms latitude in choosing which benefits of employee status to offer and which not. So long as serious efforts are made to prevent the apparent tendency for platforms to gain monopoly status within a particular sector, such an approach can work to diversify the range of platforms that can exist. In other words, the eventual lesson of the misclassification objection will be that currently objectionable platforms need to behave either more like employers or more like mere devices of communication, by either offering workers more guarantees or granting them more freedom. This creates a better environment for workers, and draws on the potential of digital platforms to offer workers greater ability to switch between ways of selling their labor - something traditionally not true of 'offline' employment in traditional firms, where exit costs for workers are high.

\footnotetext{
${ }^{8}$ For a defence of the importance of employer control (parallel with the England \& Wales judgment), see Cunningham-Parker (2016). For an endorsement of the importance of workers' freedom to choose hours (parallel with the Australian Ombudsman), see Means \& Seiner (2016).
} 
Before proceeding, let me state a few definitions, assumptions, and qualifications.

First, it will help to have a definition of what gig work actually is and how it differs from (is broader than) platform work. Gig work is any labor sold in response to discrete instances of consumer demand for the performance of specific and finite tasks. As such, gig work is paid in a piecemeal manner, for the completion of the relevant task rather than (say) the amount of time worked, often with no expectation that demand for further work will exist after the explicitly demanded task has been completed. ${ }^{9}$ Although 'gig work' is sometimes defined in ways that refer only to work sold through digital platforms ${ }^{10}$, the definition just stated is not limited to platform work even though it might include all platform work. It will prove helpful to define gig work so that it encompasses cases that are not platform work, so as to allow comparisons to be made that help establish whether platform work should be classified as gig work or as employment.

Second, in focusing on the misclassification objection I will be overlooking some other important questions about gig or platform work. Some of these concern the positive aspects of platforms. Digital platforms certainly benefit consumers by enabling the purchase of cheaper and/or improved services. Some platforms benefit both workers and consumers to the extent that employment with firms makes it harder for some talents to be brought to market. The Hayekian observation that centralized power performs poorly when making commands based on information it has collected applies not just to governments but to firms as well, particularly large hierarchical ones. ${ }^{11}$ There are anecdotal reports of skilled computer programmers being able to create value only when able to escape from a firm and onto a digital platform. ${ }^{12}$ Platforms may also offer a means for workers to escape at least some contemporary injustices of labor markets, particularly injustices of workplaces. A platform will not seek inappropriate favors from workers in return for a favorable allocation of shifts, like middle managers can. ${ }^{13}$ And the owners of a platform are not in a position to require workers to stay behind after hours to look enthusiastic, on an unpaid basis, when the bosses' preferred political candidate

\footnotetext{
${ }^{9}$ A referee points out that the time/task distinction may not hold up under scrutiny. After all, completion of tasks still involves surrendering of time. While I agree about the inexactness of the distinction, it is nevertheless accurate as a description of how gig work is in practice measured and paid, and how it therefore counts as a different section of the labor market from employed work. This is compatible with the distinction not being ultimately accurate as a way of demarcating actual types of work as such. ${ }^{10}$ See Balaram, B., Warden, J. \& Wallace-Stephens, F. Good Gigs: A Fairer Future for the UK's Gig Economy (London: Royal Society for the encouragement of Arts, Manufactures and Commerce, 2017) available online at: $<$ https://www.thersa.org/discover/publications-and-articles/reports/good-gigs-a-fairer-future-forthe-uks-gig-economy> (accessed 05.30.2019). This narrow definition seems to at play in recent philosophical summaries, including the view that "the gig economy did not exist before 2005" - see McPherson \& Satz (2019: 386). For descriptions of gig work fitting the broader definition I use here, see Stewart \& Stanford (2017: 422); Prassl \& Risak (2015: p624). More elaborate definitions of platform work have recently developed, emphasizing the way in which platforms may exert power in a distinctive way - see for example Vallas \& Schor (2020).

${ }^{11}$ This explains why firms in a competitive economy are limited in size, and why there is not just one big firm doing everything. See Coase (1937).

${ }^{12}$ See Kessler (2018: pp.21-26).

${ }^{13}$ Though platforms do facilitate ways in which workers can be similarly pressured into doing things that they might be entitled not to do. See section 4 , below.
} 
makes a televised campaign appearance in the workplace. ${ }^{14}$ Generalizing, platforms are unlike workplaces in that their owners do not enjoy the same levels of control over the physical spaces in which workers carry out their tasks. ${ }^{15}$ These benefits would need to be weighed against the negative aspects of platform work in any analysis more comprehensive than that offered here.

I will also bracket questions about negative aspects of platform work that are not part of the disputes about classification. Among the worries that I won't discuss here are that gig work is objectionable just because of its 'merely contractual' nature, ${ }^{16}$ that a growing gig economy might suppress training traditionally provided by employers with a long-term investment in workers, ${ }^{17}$ and whether properly regulated firms can confer goods on workers that might be lost in the case of platform work. ${ }^{18}$ I shall also not directly confront the concern that platforms work to push down wages, creating space for concerns about exploitation. The tendency to drive down wages is undeniable for any device that removes barriers to entry for labor, which is often what platforms do (though a minority of platforms may in fact be pushing up wages by allowing talented workers to escape from firms ${ }^{19}$ ). I shall, however, address this concern indirectly by focusing on the problems associated with digital platforms gaining a monopoly position, something that likely exerts downward pressure the earnings of their workers.

As a guide, here is how the rest of this paper is structured: Section 2 outlines an account of the employer/freelancer distinction designed to bring clarity to misclassification disputes. In proposing this account, I offer various examples of how individual digital platforms withhold relevant freedoms from workers, in ways that raise doubts about whether the platforms are really the brokers of freelance labor that they purport to be, rather than employers. Section 3 develops further points about the nature of the employer/freelancer distinction, leading to the following positive proposal: The regulation of platforms should involve a requirement that workers be offered security (principally the prospect of a defined wage payment at regular intervals) commensurate with the extent to which they cede freedoms. Section 4 explores the question of whether platforms ought to repair imbalance in the freedom/security tradeoff in the direction of offering workers more freedom or (instead) more guarantees. Here I argue in favor of diversifying rather than homogenizing the labor market where digital platform work is concerned. This is likely to secure a fairer distribution of freedoms and securities one way or the other, while also preserving a variety of different opportunities for workers whose preferences for freedom or security are in any case bound to vary.

\footnotetext{
${ }^{14}$ Here I have in mind Mitt Romney's visit to a coal mine as part of his campaign for the 2012 US presidential election. For details on this case see Bagentos (2013).

15 For a larger discussion of workplace injustice with a richer set of examples see Anderson (2017).

16 On this see Gardner (2018).

17 On this and some related concerns see Friedman (2014: 183-184).

18 Some candidate non-monetary goods of work, such as access to a community, may require (or be promoted by) workplace attendance. For discussion see Gheaus \& Herzog (2016).

${ }^{19}$ For some cases fitting this description, see Kessler (2018).
} 


\section{The nature and purpose of the freelancer/employer distinction}

As I have said, gig work and digital platform work are not equivalent. There is a long history of workers selling labor directly to customers, being paid for the discrete task demanded, without an employer or firm involved. So defined, gig work existed long before the evolution of legally defined employment as we now know it. ${ }^{20}$ Categories of gig worker that predate digital platforms remain familiar today, like plumbers, electricians, and gardeners. While some of these workers now sell their labor through a platform like Taskrabbit or Airtasker, gig workers in the past used devices like a printed phone directory advertising space in a newspaper. Such devices are still platforms, just of a less sophisticated kind. Nevertheless, the misclassification objection is in practice almost always applied to digital platforms whose workers generally lack the option of using pre-digital platforms. (For convenience, I will continue to use 'platform worker' to refer to workers who sell their labor through digital platforms.)

In these familiar but older instances of gig work, the workers are classic examples of freelancers. ${ }^{21}$ As such, these cases are helpful in suggesting what sort of content the employer/freelancer distinction ought to have. And they enable comparisons with platform workers that can help establish whether the latter kind of worker ought to be categorized alongside these more classic cases of gig worker, or whether they count as employees as per popular expressions of the misclassification objection.

It bears emphasizing that there does not exist a philosophically elaborate account of what the employee/freelancer distinction is supposed to be and why it is important. Generally speaking, employment law in most jurisdictions tends to emphasize ideas of control and dependency. ${ }^{22}$ Workers are more likely to qualify as employees when they are subjected to a significant amount of direction by the parties paying them for labor, and/or when they sell their labor to just one party, on whom they become dependent for income. ${ }^{23}$ Legislation typically leaves it to courts to work out the boundaries, this being driven by cases where the status of workers is a matter of dispute. This approach has much going for it, as an attempt to settle everything at the legislative level may increase the ability of

\footnotetext{
${ }^{20}$ A standard historical view is that "labor law is an offspring of the social and political action of the working class movement" that gained momentum once workers began to organize following the industrial revolution. See Spector (2006: 1119).

${ }^{21} \mathrm{~A}$ referee plausibly observes that many of these older types of work are more skilled than much current platform work, plumbers for example being subject to certification and training before they can trade under this label. While I do not make much in this paper of the distinction between skilled and unskilled work, the fact that much platform work is unskilled bears on the ability of platforms to offer low wages. ${ }^{22}$ It's possible that the legal idea of employer control has been historically subject to a narrow interpretation that does not anticipate the kinds of control attempted by digital platforms. For discussion of the role played by control and dependency in existing law, see Acevedo (2018), Cunningham-Parker (2016), Pinsof (2016).

${ }^{23}$ These factors can come apart: Workers may have a single buyer of their labor who happens not to direct them much, such as a proof-reader whose entire work is for a single publisher. This has motivated proposals for the creation of an intermediate category of worker, such as a 'dependent contractor'. For some discussion of what can and can't be achieved by the creation of intermediate categories along such lines, see Harris \& Krueger (2015); Cherry \& Aloisi, (2016); Davidov (2012: 181-185). In what follows, everything I say is compatible with the creation of this intermediate category, or with its non-creation.
} 
evasion later on. Relying on judicial discretion (or some other ex post agency) can use whatever determinacy is provided by legislation while being responsive to actual cases that may not be foreseeable by legislators. ${ }^{24}$ In the case of platform work, legislation was often written before the emergence of smartphone technology and therefore its applicability is more a matter of luck than of genuine anticipation. ${ }^{25}$ Nevertheless, courts have to settle disputes using some rationale, and if the legislation is indeterminate then some sort of 'purer' philosophical reasoning may be necessary. This brings us back to the points made at the outset of this paper: Existing legislation does not (and perhaps should not) fully specify when someone is working for themselves and when they are working for an employer. But even if there are reasons not to try and embed a philosophical theory of the employee/freelancer distinction into legislation, such a theory will still be needed when the time comes to actually settle the disputes that arise.

I will now proceed by just stating central elements of the employee/freelancer distinction as I propose to understand it, and use comparisons between classic gig workers and contemporary platform workers to defend the centrality of each element. In each case, I will identify a specific labor market freedom that freelancers possess in return for giving up the guarantees granted to employees who lack that freedom (or possess it to a lesser degree). Each of these freedoms is, at least in practice, often denied by digital platforms to the workers using that platform, in spite of narratives promoted by platforms about their workers being entrepreneurs or freelancers. Proceeding in this way will vindicate the misclassification objection to a certain degree, namely, according to how many of the core freedoms are being denied to platform workers in actual cases where misclassification is asserted, as well as adding some substance to the employer/freelancer distinction. Towards the end of the section I will bring together the various elements to say something about what the overall moral purpose of the distinction might be.

Being employed by a firm means gaining access to something like the following set of guarantees. One of these has already been mentioned, namely that an employee can expect a certain amount of pay proportionate to how much time they give up. ${ }^{26}$ On a rainy day in an outdoor theme park, employees might simply sit around without serving any customers, having few other tasks to which they can be assigned. In one sense, these employees have been unproductive, because they have not provided labor to satisfy some demand. Conventionally, however, these workers will have put in a day's work and been 'on company time', so they will take home a day's wages (in most jurisdictions, employment law would prevent the employer from simply sending the workers home without pay). It is in this sense that employees are paid according to 'time worked' rather

\footnotetext{
${ }^{24}$ Here I follow Davidov (2012: 174-175) and (2017: 9).

${ }^{25}$ Here I follow Stewart \& Stanford (2017: 425). For more comment on the tendency of legislation to be indeterminate as to worker classification, see Prassl \& Risek (2015: 620; 628).

${ }^{26}$ I set aside the question of how this time should be delineated - for example, whether a grocery store workers' commute to work should be regarded as time spent working, which in practice it typically is not.
} 
than 'tasks completed'. ${ }^{27}$ Another guarantee of employment in many jurisdictions is that workers will be paid a minimum wage per the unit of time worked. Among other guarantees are benefits like sick pay, annual leave entitlements, pension contributions, the right to unionize, and the right to a notice period in the event of being dismissed. ${ }^{28}$

The range and extent of these guarantees varies across jurisdictions. By and large, however, some combination of guarantees like those just listed are what workers willingly forego when they opt to become self-employed. A plumber or electrician whose services are not purchased is not in the position of the theme park employee on a day when no customers show up - they simply don't earn any money. Some guarantees enjoyed by employees are not even conceivable where freelancers are concerned, just because there is no employer who can absorb the cost of the guarantee in question. While a plumber has a right to stop work in order to take a holiday, it is not meaningful to say that this is a benefit made available by the law even if the law required freelancers to withdraw their services for some number of days 'holiday' each year. It may still be possible to create legislation aimed at making self-employed workers better off in ways not shared by employees, for example through income tax breaks. There may also be paternalistic justifications for laws against agreeing to perform particularly hazardous work, or as an attempt to give freelancers the assurance that they will not put themselves at a competitive disadvantage when declining certain tasks. But these are best thought of as reductions in costs or burdens incurred when trying to sell labor, not as guarantees in return for a contractual commitment to sell one's labor.

What sort of freedoms, then, do freelancers gain when they cede the guarantees granted to employees? These are worth identifying separately. In doing so I will include some of the criteria deemed significant by recent court or other governmental decisions mentioned at the outset. While classic gig workers may have retained all of the freedoms I shall describe, digital platforms often operate so as to deny at least some of these freedoms. This may account for why the misclassification objection is not always obviously correct when applied to any given digital platform. It also has some theoretical significance: Because the freedoms definitive of freelance work can come apart, we should doubt whether the distinction between employers and freelancers can ever be a genuinely binary one, as opposed to a spectrum on which workers are located according to which combination of freedoms and guarantees they happen to possess. This bears heavily on how we should go about actually addressing the misclassification problem.

\section{The right to negotiate with customers on price}

\footnotetext{
27 There is historically a presumption that, in addition for being paid according to time rather than satisfaction of demand, employees also have an entitlement that they will indeed put in some time and be paid for it, rather than called on to work only when the employer seeks to satisfy some customer demand. The emergence of so-called 'zero hour' contracts in the UK are, controversially, putting pressure on this convention.

28 This is one of the more elusive guarantees in the evolution of labor law, at least in the US where there is a tradition of 'employment at will'. On this see Bagenstos (2013: 244).
} 
A hairdressing business decides what the customer is asked to pay for a haircut. Its employed hairdressers do not have this kind of control. A freelance hairdresser, on the other hand, will get to set their own price, and indeed might negotiate with any customer not immediately willing to pay it. To be self-employed is partly a matter of retaining this right, even if employed and freelance hairdressers are essentially performing the same work.

A plumber's freedom to negotiate on price means there is no rule about what they must charge when (say) repairing a broken toilet. This is in stark contrast with the operating practice of many digital platforms, such as Uber, Foodora, and Deliveroo. Workers who sell their labor through such platforms are, according to the owners of such platforms, merely using the platform to establish contact with customers to whom they sell their labor. As anyone with experience with these platforms will realize, the price of purchasing the labor of an Uber driver or Deliveroo rider is determined by the algorithm embedded in the app, not by independent offers from drivers or riders. As noted, this is the source of at least some actual expressions of the misclassification objection aimed at these platforms.

Imagine now a printed newspaper or magazine that sold advertising space to traders whose services could only be offered at prices based on the newspaper's own determination of what they were worth. Very often, this would not be an appropriate way for an advertising medium to behave, the reason being that it has no business interfering with, rather than promoting the communication of, the seller's product. If the newspaper were willing to offer certain guarantees in return, such as pay in the event of a shortfall in demand for the advertised services, then their behavior might be reasonable. But that would just be for the newspaper to become more of an employer of plumbers than a device of communication. Analogously, platforms in the digital era that make similar demands are not respecting the purported freelance status of their workers.

The strength of this analogy with printed media advertising varies with how the details are filled out. Such variation, however, is instructive. One can image a general-purpose newspaper with a particular political orientation, which needs to maintain a certain identity that might be incompatible with certain services being advertised in its pages (while it is hard to imagine this being true of plumbing services, it might be true for other services). This may result in a range of conditions being attached to any sale of advertising space. On the other hand, the pre-digital platform era saw the existence of printed media whose sole function was to facilitate communication, such as the Yellow Pages, along with some publications that only carried advertisements for very specific goods or services, such as used cars. These publications carried little by way of a brand identity, but stipulations on price may have been defensible if publication was supposed to be at the luxury or affordable end of the market, and where the inclusion of an advertisement signaled something distinctive about the good or service being offered. One can imagine a sports car magazine excluding advertising from manufacturers whose vehicles are not of high performance, particularly as their inclusion would risk 
undermining the magazine's integrity. What these variations suggest is that the ability of a platform to attach conditions to advertising decreases, the more accurate it becomes to describe the platform as merely a device of communication aimed at facilitating transactions and not as a more elaborate publication that simply includes some such facilitation constrained or modified by other goals. For digital platforms that do insist on being a mere device of communication, the case for retaining an ability to make stipulations may be weakened by the platform's own stipulation about what its function is.

The question of whether a platform might stipulate prices warrants some mention of how the gig economy differs from the so-called sharing economy. The rise of apps like Uber and Deliveroo has been paralleled by an emergence of technologically similar platforms like Airbnb, through which homeowners share use of their real estate. One way of distinguishing between the likes of Uber and Airbnb is that while the former involves selling labor, the latter involves renting out physical capital, namely a home. Admittedly this distinction is inexact, as the sharing economy often involves a labor input from the supplying user: Airbnb suppliers need to clean their home prior to renting it, though they can pay Airbnb to contract a worker to do it for them. But lack of an exhaustive distinction between the gig economy and the sharing economy is not problematic. What matters is that Airbnb does not try to dictate the price of the transactions it facilitates. A homeowner is free to charge at whatever price they choose, and succeed or fail to find a customer accordingly. Airbnb does use an algorithm for prices, but this is merely to advise on what price might be attractive to consumers, given the neighborhood, time of year, a home's number of bedrooms and bathrooms, and so on. This contrasts with the pricing algorithm for Uber, Deliveroo, etc. which is inescapable. Airbnb's business model has not given rise to any version of the misclassification objection. I suspect that this is largely due to the willingness of Airbnb to respect a homeowner's right to set their own price for sharing their property. The case of Airbnb also suggests a platform's insistence that it is not they who set prices, but 'the market' is irrelevant: Whatever the market price might be, it is a freelancer's right to sell their services at a higher (or lower) rate regardless, and sink or swim. After all, 'the market' is really just the agglomeration of participants offering to transact at various prices, and not some sort of prior independent force.

Another practice sometimes used by Uber is to conceal a customer's requested destination until after a driver has accepted the request based on knowing only the distance to be covered. Although this is not really about what price can be charged, this could be construed as further denial of an essential ingredient in negotiations, namely knowledge of what a customer is asking for. Nobody would expect a freelance electrician to put up with having to accept or decline work knowing only where a customer's home was located, and not which electrical device needed attention.

Whether it is right to say that a platform employs its workers just because that platform denies the worker a freedom to negotiate on price remains open to question. This is because the right to set a price is not the only freedom that should be embedded in the 
freelancer/employer distinction. If a platform grants various other freedoms, such as the ones I am about to mention, then there remains a case for treating that platform as closer to a facilitator of freelance transactions than as an employer, even if it denies workers the freedom to negotiate on price. As I have said, I shall come back to the question of what to say about platforms that respect the freedoms of freelancers partially but not entirely, which may be what many platforms are actually doing. ${ }^{29}$

\section{The right to autonomous capital investments}

Like an employee of a firm, a classic freelancer usually sells their labor with the help of some capital. Carpenters, electricians and gardeners utilize tools and equipment that augment or enable their skills. Freelancers must make decisions about which types of equipment to purchase and how much money to invest. But they make such decisions with freedom. ${ }^{30}$ Continuing the analogy from earlier, any platform that merely exists to help freelancers communicate with customers has no right to deplete this freedom by setting its own boundaries or requirements on capital investments. A newspaper carrying advertisements for plumbers has no entitlement to dictate when a plumber replaces their tools or which brand they use, except when such stipulation advances one of the newspaper's other goals besides communication, or to communicate some specific type of plumbing service (something that, recall, digital platforms are effectively ruling out when they self-describe as mere devices of communication). Firms, on the other hand, decide which sorts of capital are used by their workers, though it is also the firm that carries the necessary costs of investing in that capital. ${ }^{31}$ This is not arbitrary: For some employers, consistency of capital offers an important way of maintaining a consistent or product and/or one differentiated from that offered by competitors. Indeed, digital platforms can do this as well: In Australia, a platform called Sheba offers female customers exclusive access to a pool of female-only drivers. This platform, though, carries a clear and defensible identity associated with a sub-category of rideshare service. This is not to say it is thereby an employer: Although it excludes some workers and customers (male ones), it is not trying to deplete the freedom of the workers who actually sell their labor through that platform. In this respect it resembles the case of the printed sports car magazine denying advertising space to manufacturers whose product does not meet the standards of a sports car.

At least one digital platform imposes quite strong controls over the capital investments of workers who use it. In order to drive with Uber, one must agree to use a car falling within quite strict restrictions as to its age and model. One cannot simply offer rides with

\footnotetext{
${ }^{29}$ Although I have focused on the way in which platforms control pricing, a lot more could be said about the way in which platforms have been able to exert authority over workers through the design and use of the relevant algorithms. On this see Tomassetti (2020).

${ }^{30}$ Safety considerations may require or prohibit certain types of equipment. Such rules are set not by platforms but by independent agencies or legislators, who may be presumed to not have a financial stake in the transactions taking place.

${ }^{31}$ Labor law sometimes grants firms a right to require that employees absorb these costs, e.g. purchase of uniforms. The justification for this will depend on there being other guarantees that firms provide.
} 
any old vehicle. In addition, Uber supplies its drivers with a variety of 'guidelines' as to the interiors of their cars, such as the provision of bottled water and mints, and has reportedly even told drivers to avoid talking about contentious topics with riders. ${ }^{32}$ While these extra guidelines may not be made as explicit commands, there is a case for regarding them as implicitly enforced - a point I will defend more properly later in this section. Suffice it to say, though, that the analogy with classic gig work holds once again: A pre-digital platform like a newspaper or magazine would not be in a position to require a freelancer advertising in their pages to use or not use certain kinds of tools, much less to supply a customer with a specific kind of edible item. As an aside, the convention in many countries is that a consumer offers a cup of tea or coffee to a visiting trader whose labor they are purchasing, rather than the other way round. The demandingness of Uber's restrictions goes beyond what might be reasonably imposed on safety grounds and is therefore apparently a means of securing consistency or differentiation with respect to Uber's product.

\section{The right to 'self-brand'}

A characteristic of many employees' working life is a requirement to wear a uniform or follow a dress code. The reasons for this vary. Uniforms worn by flight attendants and retail staff allow customers and co-workers to know who's who, which can be important. Uniforms and dress codes also help a firm to promote a brand or image in ways that might be difficult if workers just wore whatever they felt like. (Again, this is about product consistency and differentiation.) Of course, there are limits to what a firm can demand of an employee's appearance, and firms sometimes impose unjustly high demands. Some firms don't seek to make such demands, perhaps as a way to make employment with them more attractive. The general point, though, is that a right to impose some requirement on workers' appearance, albeit within limits, is a fairly standard element within the range of commands that firms can legitimately impose on workers in return for a guaranteed wage and associated package of benefits.

At least some digital platforms behave like firms in imposing appearance requirements on workers selling their labor through the platform. A case in point is the platforms through which workers sell bike-riding labor, typically to deliver food from restaurants to customers' homes. Riders using platforms like Foodora and Deliveroo must wear brightly-colored attire carrying the platform's logo, along with a similarly-branded backpack. Notably, such requirements do nothing to promote the quality of service provided - bright attire does not help the food arrive sooner or in better condition. By and large, the branding really just serves to make the platform more visible to other potential customers, namely members of the public who might see the branded riders out and about.

If riders selling labor through the likes of Foodora and Deliveroo really are freelancers, then it's unclear why they should be expected to work under such requirements. Again,

${ }^{32}$ See Bloodworth (2018: 224-225). 
nothing like this would be expected of classical gig workers: A plumber would not be expected to wear clothing displaying the brand of whatever platform they used to sell their labor, or the brand of any company supplying the capital they use. And this is because firms generally only have the right to impose uniform or other appearance requirements when they are employing the workers on whom the requirements are imposed. Again, this is due to the trade-off where firms agree to provide guarantees not enjoyed by freelancers in return for being able to direct workers in ways not reasonably asked of freelancers.

\section{The right to persist in trading}

Among the more noticeable and innovative features of smartphone apps is the embedded rating system whereby customers and workers can both evaluate each other. Arguably this has enabled platforms to enhance the service they facilitate, particularly in the case of ridesharing. At the same time, it has provided platforms with a pretext for expelling workers from the platform, should their ratings become low enough. This has given platforms a degree of leverage that may exceed what they can reasonably impose without being employers.

Generally speaking, freelancers have a right to sell their labor to anyone willing to pay for it. This means that freelancers can continue to sell their labor even when its quality falls below that of competing freelance workers. Although freelancers might accrue a reputation for sub-standard quality of service, this is not grounds for their exclusion from the market. ${ }^{33}$ Ideally, a competitive market with sufficient flow of information will mean customers find out which workers offer the best quality. Workers will be forced to offer a lower price if their service is known to be of lower quality, but this gives customers more choice ('quality' is in any case often a subjective matter).

An employer has some power to fire (or at least discipline) a worker who consistently delivers a poor service. But a platform classically does not. To re-apply the analogy yet again, a newspaper in the pre-internet age would not conventionally be permitted to block a plumber whose services were not highly rated by customers. At most, they would be permitted to include information about past customer ratings alongside any advertisement purchased by that plumber. Digital platforms work differently: Platforms like Uber are in a position to easily track the ratings accrued by drivers. Should a driver's rating fall below a threshold, Uber has the power to simply block them from offering their labor by shutting them out of the app altogether, without warning or any right of

\footnotetext{
33 One complexity here is that freelance workers can and do form associations so as to self-regulate and ensure certain standards. Since workers can be barred from entering these associations of expelled from them, they can have an exclusionary character, though likely not in the manner of that used by digital platforms (not least because self-regulation would allow workers to retain collective control over the criteria for exclusion).
} 
protest. ${ }^{34}$ Again, this conduct puts Uber closer to the role of employer than to mere facilitator of transactions.

A platform's ability to expel a worker is compounded by the apparent tendency for successful digital platforms to gain a monopoly position. If Uber drivers could easily find an alternative platform, then expulsion due to low ratings would be less objectionable. And platforms may well refrain from such practices if they were in a position of having to compete to attract workers. The general point is that the burden of justification should be against any such power existing. There may be nothing wrong in principle with a rating system so long as it communicates reliable information. ${ }^{35}$ But it should not be in the power of platforms, as opposed to employers, to prevent freelance workers from continuing to sell their labor.

\section{A Positive Proposal: Platforms Can't Have it Both Ways}

So, what is the basic point of the employer/freelancer distinction? I have proposed that the distinction be reduced to a cluster of freedoms that are surrendered, at least to some degree, by workers who agree to employment by a firm rather than work for themselves, where such surrendering is compensated by the guarantees embedded in an employment contract. The freedoms I have described include a right to negotiate with customers on price, a right to make one's own decisions when it comes to capital investment, a right to autonomy over one's appearance while at work (principally a right not to carry the brand of any platform) and a right to persist in trading in spite of low customer ratings. It is likely that this list of freedoms is not exhaustive, but each of them represents a freedom very often ceded to employers in real labor markets. Whether the freedoms I have listed have some theoretical connection with each other, as opposed merely to a history of being enjoyed by freelancers, is not wholly clear either. But it is possible that the ceding of each of these rights to a firm has something to do with the way in which firms are conducive to the efficient production of certain goods and services. While the orthodox theory of the firm holds that firms exist because they economize on transaction costs (as, notably, do digital platforms), they do so largely by their ability to direct workers in ways not feasible in an economy where all labor is freelance. Notably, the ceding of freedoms listed here is of a sort where workers thereby become directed, which is a principal explanation for why firms come to exist at all. ${ }^{36}$ I have not sought to defend a view on what sort of balance the employer/freelancer distinction should seek to achieve. That is, I have stayed neutral on how morally problematic it is that employment means ceding autonomy to a set of

\footnotetext{
${ }^{34}$ For some description of how Uber has practiced expulsion, see Prassl \& Risak (2015: 638).

35 More could be said about rating systems, particularly in relation to how to construe the sort of freedom they undermine. Deepa Acevedo plausibly observes that workers under pressure to secure a good rating may become obsequious towards customers, and notes that this may be evaluated as a loss of freedom from domination rather than from interference (2018: 816).

${ }^{36}$ See Coase (1937) for the classic statement of this theory.
} 
bosses, and how far firms must go in providing guarantees in order to mitigate that. ${ }^{37}$ I have merely sought to argue that the content of the employer/freelancer distinction just is a matter of trading certain types of freedoms for certain types of guarantees. One does not need a detailed view about where the balance lies in order to conclude that something has gone awry when a platform requires workers to cede freedoms without providing guarantees, and yet declares itself merely a piece of communications technology through which labor is sold on a straightforwardly freelance basis.

I suspect the basic moral value of maintaining the employer/freelancer distinction lies in two features. First, there is its capacity to promote a range of options in the labor market. Broadly speaking, people are different, and the differences between them extend to preferences for how they sell their labor. Some people have a taste for risk and value being their own boss. Freelance work appeals to such people. Others prefer security and are willing at accept a degree of direction in return, or value membership in an organization with co-workers. These people seek employment. A liberal society should make room for both kinds of people, and regulate its labor markets accordingly. Second, and more important where this paper's subject matter is concerned, there is a consideration of fairness: If an owner of capital is going to provide guarantees to those who sell their labor by working on such capital, then it is fair that they get to make certain commands in return. A supermarket chain that agrees to absorb the cost of paying workers during lean periods has at least a defeasible case for requiring workers to wear a uniform. But if the owner of a piece of capital, like a platform, is going to expect workers to absorb the costs of uncertainty about demand, then it surrenders such rights accordingly. This is just a basic point about what's fair when it comes to balancing liabilities and privileges in the labor market.

The misclassification objection gets its substance from platforms having been able to have things both ways: They get to behave like employers when it comes to directing workers, which means depriving workers of relevant freedoms, and get to behave like mere brokers when it comes to not providing workers with relevant guarantees. The problem with some digital platforms, then, is that they subvert a distinction that is important in providing a fair balance of benefits and burdens between sellers of labor and owners of capital, in ways compatible with there being a range of different combinations of these benefits and burdens that are both fair. (As I shall explain later, it is plausible to treat the employer/freelance distinction as more of a spectrum, in view of the fact that different combinations involve different degrees of freedom and security.)

The proposal being offered, then, is that digital platforms treat workers justly so long as they offer a fair balance between the security they grant and the freedoms they take away. One might wonder, however, where this leaves the variable of expected monetary

${ }^{37}$ One view is that there are moral problems with firms per se, because employment contracts are inherently subordinating. Authors that come at least close to defending this view are Collins (2018) and Lee (2018). 
compensation itself. ${ }^{38}$ As noted, real world expressions of the misclassification objection, and indeed concerns about the digital platform economy in general, are often motivated by concerns about the incomes received by workers. These incomes are sometimes lower than the legal minimum wage. The framework being offered might appear to leave expected compensation out of things. At any rate, we might ask whether a platform that simultaneously suppressed freedom and denied security to its workers would be treating these workers unjustly under conditions where expected financial compensation was nevertheless high.

While such conditions are a conceptual possibility, it is first worth noting that, at least in practice, the way in which platforms suppress worker freedom very often works to reduce their expected compensation as well. This is especially true of the freedom to negotiate with consumers on price. When a platform's algorithm dictates what a worker can earn from a transaction, then this may in practice suppress their expected compensation. Platforms that do not deprive workers of this freedom, such as AirTasker and Upwork, where workers are allowed to make price offers based on their skills and reputation, enable some workers to gain greater financial compensation than they might expect through an employer, or through a platform exerting more control over the pricing process. Given this, at least some (probably many) cases where platform workers have low expected compensation count as unjust under the proposal being offered. This leaves it open as to whether the level of expected compensation should always be decisive in ways that might override an unfair balance of freedom and security. One might still think that if workers earn enough, the facts about freedom and security diminish in significance.

I suspect the closest sort of case to one where expected compensation is high in spite of a platform suppressing freedom is that where there is very low worker supply relative to consumer demand. This sort of case is familiar from the somewhat notorious practice of 'surge pricing' associated with rideshare apps. Here the notoriety is connected with the feeling that consumers are being gouged or overcharged. ${ }^{39}$ But insofar as surge pricing transfers greater earnings to the workers, this may indeed undermine the feeling that they are treated unjustly by the platform. This would appear to support the intuition that monetary compensation may ultimately be more important than the freedom/security balance.

Surge pricing is designed to be temporary and in any case platforms might not pass on a great deal of the extra revenue to the drivers. These facts aside, I think there is at last one general consideration against the view that monetary compensation as an independent third variable on a par with the freedom and security variables being offered. Here we might consider the case of digital platform workers who choose to work rather

\footnotetext{
${ }^{38}$ I thank an anonymous referee for encouraging me to spend more time on this point.

${ }^{39}$ I will not attempt to discuss the merits of this intuition. A useful discussion of price gouging and the role played by high prices as a means of inducing an increase in supply, albeit not in the context of platform work, is Zwolinski (2008).
} 
infrequently. In the case of rideshare drivers, such workers often have relatively wellpaid and secure employment through which they gain the bulk of their income, or else might be retired and/or independently wealthy. (Note that I do not rely here on any claim that such drivers are especially common, only that they can exist.) The genuinely casual Uber driver is, of course, treated the same by the platform as any other driver when it comes to the terms that the platform offers them. It is plausible, however, that they are not treated unjustly. Why is this? A plausible answer, I feel, is that in being a very casual driver it is not accurate to say that the platform has withheld the security that a worker can expect from an employer: By offering very few work hours, occasional workers are not dependent on the platform in ways that make it meaningful to ask whether their income is secure or not. It is only workers who offer a large amount of their time who can be characterized as having surrendered a good deal of personal freedom in return for a lack of security. For a minority of privileged individuals, Uber work can represent something like a 'side income' or even a quasi-hobby. The trouble, however, with treating expected compensation as decisive is that it is harder to avoid disqualifying these workers as victims of injustice. This is because the idea of expected compensation is specific to individual transactions, meaning transactions involving occasional workers still count. By contrast, the proposal I am offering about the balance of freedom and security is more linked to the ongoing relationship that a worker has with a platform, and allows workers who contribute large portions of their time to be viewed differently: It is these workers who are in a position of having insecure work, and who can be viewed as treated unjustly until this work is either made more secure (by the granting of employment status) or else subject to the freedoms associated with other kinds of freelance work that might be insecure but subject to the benefits of greater autonomy.

It is hard, however, to entirely dismiss the claim that higher earnings in the face of low freedom and low security still matter when working out what justice should say about platform work. It is plausible to say that high expected compensation can mitigate the injustice of misclassification by indirectly working against a platform's ability to withhold security. A higher income is, after all, a means of gaining greater security, even if it may be precarious compared to the contractual guarantee of regular income, sick pay, etc. associated with employee status. This suggests that the dimensions of security and freedom may remain the sole variables so far as justice is concerned.

\section{Freelancing and employment as a spectrum}

It is possible to dispute the argument of the previous sections on behalf of contemporary digital platforms. Deliveroo and Uber cannot demand that workers show up for a fixed amount of time each week: Workers can simply log into and out of the app whenever they choose. This accounts for the platforms' appeal to many workers and, arguably, for much of their success with customers. While there is something to this rejoinder, its force is hard to gauge. Logging into an app is not the same thing as selling one's labor through that app. Digital platforms are designed so that workers are paid only when they accept an invitation to deliver food or provide a ride (etc.). One contention offered by workers 
is that they are actually working whenever they are logged in, or at any rate that platforms get something for nothing when offering services to customers without absorbing the cost of non-uptake. ${ }^{40}$

Here we might ask exactly what determines when a worker is strictly speaking at work. Is it taking on a task or merely signaling one's willingness to do so, either by showing up for a shift at a workplace or by logging in to an app? It may be impossible to answer this question without simply begging the question. This is because the classification of labor is already a matter of whether work consists in surrendering time (which is a feature of ceding freedom for a guaranteed wage) or completing tasks on a rolling, discretionary basis (which is not). A freelance hairdresser with no customers is, as I have said, doing the same thing as an employed hairdresser with no customers - namely sitting ready to act if someone shows up. The first hairdresser is not working but the second is, insofar as only the second hairdresser stands to get paid. Of course, there is nothing stopping digital platforms from demanding a certain number of hours logged in as part of the terms they offer workers. Given this, it is not plausible to defend platforms on grounds that they somehow can't demand a certain number of hours worked. Instead, it is plausible to say that platforms can't make such a demand consistent with treating their workers as freelancers.

A more sophisticated rejoinder, though really an implication of what I've said in preceding sections, involves the observation that the employer/freelancer distinction is almost certainly a spectrum rather than a binary opposition. Classic gig workers like plumbers and electricians typically enjoy all of the freedoms described earlier. But platforms are often guilty of denying workers only a subset of these freedoms. Uber, for example, denies freedom from negotiating on price and autonomy of capital investment, but it does not impose a requirement to wear Uber-branded clothing. ${ }^{41,42}$ This may make a significant difference. But the difference, if there is one, needn't count against the main point being defended here, which is that platforms, as owners of capital, cannot have it both ways over workers. If a worker is denied the freedoms of a freelancer, then they must (proportionately) receive the guarantees of an employee.

One way to try and make progress would be to construct some account of how the various freedoms ceded by employed workers 'line up' with the various freedoms retained by freelance workers. That is to say, perhaps there is some principled reason why accepting a requirement to wear a uniform might entail an employer requirement to offer sick pay, but (for some reason) not to offer pension contributions. If such an attempt could succeed, it would provide a systematic way of regulating platforms according to how much they direct workers and how much they continue to recognize worker freedom in ways that employers need not. But it is hard to see how any such account could be constructed without considerable arbitrariness: Really there is nothing to connect any

\footnotetext{
40 This point is emphasized in Bloodworth (2018: 232).

${ }^{41}$ Compare the conclusion drawn by Prassl \& Risak (2015: 641).

42 Uber Black drivers are, however, required to adhere to a smart dress code.
} 
specific worker freedom with a specific employer guarantee, except perhaps in ways ultimately traceable to the nature of the work itself rather than the degree of direction (for example, perhaps there is a case for treating physically demanding jobs as subject to greater sick pay entitlements or earlier opportunities to retire). Perhaps more importantly, any systematicity might come at the cost of making the overall approach quite illiberal: It is hard to see how the sort of view being described is anything other than an enormously prescriptive outlook about labor markets that would tend to homogenize the range of opportunities available to workers.

An alternative way forward takes inspiration from claims defended in the preceding section. In particular, we might prioritize the desirability of a labor market that can cater to workers exhibiting different appetites for risk, and which does something to promote protection against the sort of powers gained by platforms enjoying monopoly power. I do not mean to suggest that this can be easily done. ${ }^{43}$ It is possible that incumbent platforms with large market share have simply benefitted from high barriers to entry where competitors are concerned. If this could be addressed (for example by granting subsidies or other temporary assistance to emerging competitors), then the industry may be rather like commercial banking, in which barriers to entry are high but where multiple competing providers may co-exist and compete once established. But it may be that monopolies in the platform sector are due to other factors. These may include the sort of network effects whereby consumers and/or workers gradually migrate to a single platform, due to positive feedback loops that improve the platform's service. In less technical language, this is the sort of thing that might happen if consumers or workers always have some reason to use the platform that has the most other users, for example because this increases the reliability of ratings or the prospects of being able to participate in a transaction most quickly.

It may prove that concerns around digital platform work ultimately favor less reliance on labor law as a device with which to ensure that workers have certain distributive entitlements met. Setting aside very general questions about what these entitlements are, the fact is that many developed economies have relied on the regulation of employers as a means of delivering entitlements that could in principle be pursued through wider fiscal policy instead. Here I have in mind the contrast between provisions internal to labor markets like minimum wage and employer-sponsored healthcare, and provisions external to labor markets like a universal basic income and universal state-provided healthcare. The (in)feasibility of regulating digital platforms may count in favor of a general shift from the first set of policy mechanisms to the second, which among other things could improve the bargaining power of workers relative to that of digital platforms even if the legal rights of platforms were left unchanged.

\footnotetext{
${ }^{43}$ I thank a referee for prompting me to take more seriously the possibility that in cases where digital platforms enjoy monopoly status, this may be traceable to the monopoly being a natural sort, i.e. one that cannot be easily broken up.
} 
The above is just to register there remain questions about what sort of policy approach would be most feasible when it comes to strengthening the relative position of workers overall. But this does not undermine the case for pursuing a more precise position on the regulation of platforms in particular. While the rise of the platform economy may indeed call for further proposals, the regulation of platforms themselves should seek to secure a fair balance between worker freedom and worker security, but perhaps subject to latitude as to how this is secured as workers and platforms decide to deal with each other. ${ }^{44}$ Simply put, any platform that fails to grant some worker freedoms should simply be required to compensate with some guarantees but for it to be left open exactly what is provided. In any case, this may fit better with the actual preferences of many workers: In any case, this may fit better with the actual preferences of many workers: The fact that workers tend to prefer full employee status to that of independent contractor is compatible with them actually wanting something intermediate that falls short of employee status. ${ }^{45}$ To the extent that a rideshare app stipulates prices but not working hours, justice may require only that some subset is offered out of minimum wage, sick pay, pension contributions and the rest of the guarantees that would be required if freedom were ceded to the level of employment.

Ultimately, this involves only a quantitative judgment about how much freedom is being ceded and how far this falls short of the critical level at which such ceding makes a worker an employee in the full sense. But it is likely that some sort of quantitative judgment of this kind is what's most effective if we are to take seriously the way in which digital platforms are somewhat but not entirely like employees. And there are several theoretical advantages to an approach of this kind. One is that digital platforms offering much the same service will be put in a position where they might differentiate themselves according to which sort of guarantees they offer their workers. They might also respond by differentiating on as to how much freedom they ask their workers to cede. The result would be a more diversified labor market, which would mean more options for workers and perhaps even for consumers. A second, though related advantage is that digital platforms have great potential to make labor markets more fluid, in the sense that workers might easily go back and forth between different mechanisms for selling their labor. Traditional labor markets have their fluidity limited by the obvious difficulties involved in switching between employers associated with a particular geographic location: Leaving a job at a factory, university, or restaurant often means uprooting oneself from other important networks and even moving home. Nobody has to move home when moving platforms, and typically won't leave any friends behind. ${ }^{46}$

\footnotetext{
${ }^{44}$ One possibility, in an article published after this one was submitted, requires that platforms pay larger social insurance contributions than regular employers, particularly when the work sold through the platform is of the more precarious sort. See Bieber \& Moggia (2020).

${ }^{45}$ Some empirical work on the preferences of platform workers suggests that while employee protections are desired by workers, there is some anxiety about how a platform might behave if granted the full powers of an employer. On this see Dubal (2020).

${ }^{46}$ Here I have been influenced by the optimistic outlook of Munger (2018).
} 
The bottom line might be that, instead of trying to work out which digital platforms must be coerced into behaving more like employers, the best way of accommodating the misclassification objection is to make platforms compete more with each other by offering different combinations of freedom and security to their workers. This means that platforms beprevented from having things both ways, but most go one way or the other - either behave like employees and provide at least some benefits, or behave more like communication devices and hold off from attempting to direct workers. Promoting the competitive conditions required to unlock the potential for diversification does mean that governments may need to work harder to break up monopolies than they currently are and, as noted above, there are difficult questions as to whether the sort of monopoly status enjoyed by some digital platforms are of the sort where breaking up is a feasible option. But it also means letting things fall as they might as to which platforms opt to accept more of the responsibilities of employers, and which opt to treat their workers like they're their own bosses. If this is done right, then there is a sense in which attention shifts from how to classify the types of workers that exist in the current market, towards a market regulated so that classification will not become a matter of dispute in the first place.

\section{Acknowledgments}

This paper began as a public lecture given at St Cross College, Oxford, in February 2019. Much of it was then written during the time I spent as Plumer Fellow at St Anne's College during the early part of that year. I am grateful to Roger Crisp, Umut Baysan, and Terry O'Shaughnessy for helping me to enjoy a productive time, and to the University of Melbourne for sabbatical leave. For helpful feedback on drafts of this paper, I thank audiences at Warwick University and the University of Melbourne, as well as participants at a workshop retreat held by the Melbourne Political, Legal and Social Theory Network, particularly Kate MacDonald who gave written comments. Kristi Olson also shared the manuscript with her seminar students at Bowdoin College, who kindly sent yet more helpful feedback (thanks here to Soren Birkeland, Jaida Hodge-Adams, Jaden Dixon and Joseph Copeland, and to Kristi for her own comments). My thinking on matters of labor market justice, including the issue of gig work, has been much aided by regular conversations with Alastair James, whose own research will likely improve on the analysis offered here. Finally I thank two anonymous referees, and the editors, for Politics, Philosophy \& Economics.

\section{Notes}

Acevedo D (2018) Unbundling Freedom in the Sharing Economy. Southern California Law Review 91: 793-838.

Acevedo D (2020) The Rise and Scope of Gig Work Regulation. In: Acevedo D (ed.) Beyond the Algorithm: Qualitative Insights for Gig Work Regulation Cambridge University Press: 15-16. Anderson E (2017) Private Government: How Employers Rule Our Lives (and Why We Don't Talk about It) Princeton, NJ: Princeton University Press. 
Bagentos S (2013) Employment Law and Social Equality. Michigan Law Review 112(2): 225-273. Bieber F \& Moggia J (2020) Risk Shifts in the Gig Economy: The Normative Case for an Insurance Scheme against the Effects of Precarious Work. Journal of Political Philosophy (online view).

Bloodworth J (2018) Hired: Six Months Undercover in Low-Wage Britain London: Atlantic Books. Cherry M \& Aloisi A (2016) Dependent Contractors in the Gig Economy: A Comparative

Approach. American University Law Review 66: 635-689

Collins H (2018) Is the Contract of Employment Illiberal? In Collins H, Lester G, Mantouvalou V (eds.) Philosophical Foundations of Employment Law New York: Oxford University Press: 4867.

Coase R (1937) The Nature of the Firm. Economics 4(16): 386-405.

Cunningham-Parker K (2016) From Amazon to Uber: Defining Employment in the Modern Economy. Boston College Law Review 96: 1673-1728.

Davidov G (2012) Freelancers: An Intermediate Group in Labor Law? In: Fudge J, McCrystal S, Sankaran, K (eds.) Challenging the Legal Boundaries of Work Regulation London: Bloomsbury: 171-185.

Davidov G (2017) The Status of Uber Drivers: A Purposive Approach. Spanish Labour \& Employment Relations Journal 6(1-2): 6-15

Dubal V (2020) An Uber Ambivalence: Employee Status, Worker Perspectives and Regulation in the Gig Economy. In: Acevedo D (ed.) Beyond the Algorithm: Qualitative Insights for Gig Work Regulation Cambridge University Press: 33-56.

Friedman G (2014) Workers Without Employers: Shadow Corporations and the rise of the Gig Economy. Review of Keynesian Economics 2(2): 171-188

Gardner J (2018) The Contractualisation of Labor Law. In Collins H, Lester G, Matavoulou, V (eds.) Philosophical Foundations of Employment Law New York: Oxford University Press: 33-47.

Gheaus A \& Herzog L (2016) The Goods of Work (Other than Money!) Journal of Social Philosophy 47(1): 70-89.

Harris S \& Krueger A (2015) “A Proposal for Modernizing Labor Laws for Twenty-First Century Work: The 'Independent Worker'” The Hamilton Project, Discussion Paper

Kessler S (2018) Gigged: The Gig Economy, the End of the Job, and the Future of Work (New York: Random House).

Lee J (2018) Contracts and Hierarchies: A Moral Examination of Economic Theories of the Firm. Business Ethics Quarterly 28(2): 153-173

Means B \& Seiner J (2016) Navigating the Uber Economy. UC Davis Law Review 49: 1511-1546

McPherson \& Satz (2019) Ethics And, In, and For Labor Markets. In: White M (ed.) The Oxford Handbook of Ethics and Economics Oxford University Press: 381-396.

Munger M (2018) Tomorrow 3.0: Transaction Costs and the Sharing Economy Cambridge University Press.

Pasquale F (2016) Two Narratives of Platform Capitalism. Yale Law \& Policy Review 35: 309-319 Pinsof J (2016) A New Take on an Old Problem: Employee Misclassification in the Modern Gig Economy. Michigan Telecommunications \& Technology Law Review 22(2): 341-373

Prassl J \& Risak M (2015) Uber, Taskrabbit, and Co.: Platforms as Employers? Rethinking the Legal Analysis of Crowdwork. Comparative Labor Law \& Policy Journal 37: 619-652.

Spector H (2006) Philosophical Foundations of Labor Law. Florida State University Law Review 33: 1119-1148.

Stewart A \& Stanford J (2017) Regulating Work in the Gig Economy: What are the Options? Economic and Labor Relations Review 28(3): 420-437.

Tomassetti J (2020) Algorithmic Management, Employment and the Self in Gig Work. In: Acevedo D (ed.) Beyond the Algorithm: Qualitative Insights for Gig Work Regulation Cambridge University Press: $123-145$

Vallas S \& Schor J (2020) What Do Platforms Do? Understanding the Gig Economy. Annual Review of Sociology 46: 273-294.

Zwolinski M (2008) The Ethics of Price Gouging. Business Ethics Quarterly 18(3): 347-378 


\section{Author biography}

Daniel Halliday is Associate Professor of Political Philosophy at the University of Melbourne. He is the author of The Inheritance of Wealth: Justice, Equality, and the Right to Bequeath (OUP, 2018) and, co-authored with John Thrasher, The Ethics of Capitalism: An Introduction (OUP, 2020). He is currently working on questions of tax justice under conditions of slow economic growth, funded by a grant from the Australian Research Council. 


\section{University Library}

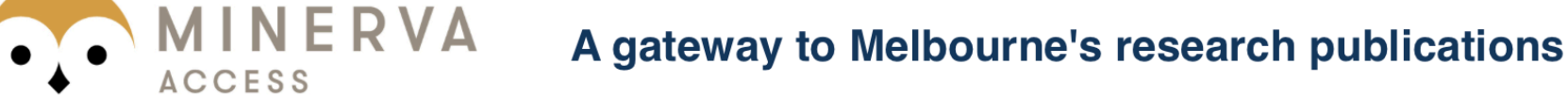

Minerva Access is the Institutional Repository of The University of Melbourne

\section{Author/s:}

Halliday, D

Title:

On the (mis)classification of paid labor: When should gig workers have employee status?

Date:

2021

Citation:

Halliday, D. (2021). On the (mis)classification of paid labor: When should gig workers have employee status?. Politics, Philosophy \& Economics, 20 (3), pp.229-250. https:// doi.org/10.1177/1470594x211015467.

Persistent Link:

http://hdl.handle.net/11343/273245 